\title{
Circuito espacial da produção e o círculo de cooperação da indústria do petróleo: O caso da Petrobras
}

Spatial circuits of production and circles of cooperation of the oil industry: The case of Petrobras

Le circuit spatial productif de l'industrie pétrolière: Le cas de l'entreprise brésilienne de pétrole(Petrobras)

Circuito de producción espacial y círculo de cooperatín de la industria petrolera: El caso de petrobras

\section{Francismar Cunha Ferreira e Cláudio Luiz Zanotelli}

\section{(2) OpenEdition}

\section{Journals}

\section{Edição electrónica}

URL: http://journals.openedition.org/espacoeconomia/18262

DOI: 10.4000/espacoeconomia.18262

ISSN: 2317-7837

\section{Editora}

Núcleo de Pesquisa Espaço \& Economia

\section{Refêrencia eletrónica}

Francismar Cunha Ferreira e Cláudio Luiz Zanotelli, «Circuito espacial da produção e o círculo de cooperação da indústria do petróleo: O caso da Petrobras», Espaço e Economia [Online], 20 | 2020, posto online no dia 05 janeiro 2021, consultado o 29 janeiro 2021. URL: http:// journals.openedition.org/espacoeconomia/18262 ; DOI: https://doi.org/10.4000/espacoeconomia. 18262

Este documento foi criado de forma automática no dia 29 janeiro 2021.

\section{c) (1) ()}

Espaço e Economia - Revista brasileira de geografia econômica est mise à disposition selon les termes de la licence Creative Commons Attribution - Pas d'Utilisation Commerciale - Partage dans les Mêmes Conditions 4.0 International. 


\title{
Circuito espacial da produção e o círculo de cooperação da indústria do petróleo: 0 caso da Petrobras
}

\author{
Spatial circuits of production and circles of cooperation of the oil industry: The \\ case of Petrobras \\ Le circuit spatial productif de l'industrie pétrolière: Le cas de l'entreprise \\ brésilienne de pétrole(Petrobras) \\ Circuito de producción espacial y círculo de cooperatín de la industria \\ petrolera: El caso de petrobras
}

Francismar Cunha Ferreira e Cláudio Luiz Zanotelli

\section{Introdução}

1 A pesquisa analisa os aspectos geoeconômicos da indústria do petróleo a partir do conceito de circuito espacial da produção. Nesse contexto, objetiva-se compreender a singular organização espacial e produtiva do circuito do petróleo que no movimento de valorização de capital desenvolve uma divisão social do trabalho e uma organização espacial específica, bem como produz e condiciona, em diferentes escalas, uma série de fluxos materiais e imateriais no espaço geográfico e implica em diversos efeitos sociais, econômicos, ambientais que em última instância contribuem para a produção e conformação de um espaço desigual e combinado.

Utiliza-se como estudo empírico o grupo Petrobras e suas relações com outras empresas locais, nacionais e multinacionais. O grupo Petrobras é uma sociedade anônima de capital aberto, controlada pelo Estado brasileiro que detêm $50,2 \%$ de seu capital votante e atua nos segmentos upstream (concentra as atividades de exploração e produção de óleo e gás), midstream (atividades ligadas ao refino e a produção de derivados de petróleo) e o downstream (transporte, distribuição e comercialização dos derivados do 
petróleo). Na presente pesquisa teremos como enfoque de estudo o setor de produção (upstream) de petróleo e gás natural.

3 Metodologicamente, o artigo faz uma breve revisão da bibliografia sobre circuito espacial da produção e seus círculos de cooperação empresarial, com destaque para o setor do petróleo. Empiricamente, foi realizado um levantamento de informações e dados junto aos relatórios anuais de sustentabilidade da Petrobras como volume de produção de petróleo e gás, número de trabalhadores próprios e terceirizados e etc. Junto a Agência Nacional do Petróleo (ANP), da Empresa Brasileira de Energia (EPE) e do Instituto Brasileiro de Geografia e Estatísticas (IBGE) e em trabalhos de campo foram realizados levantamentos das infraestruturas e das plantas industriais em terra e no mar da Petrobras existentes no território nacional a fim de identificar a organização espacial e produtiva do grupo e do circuito do petróleo no Brasil. Além disso, ainda junto ao IBGE (2010), foi realizado o levantamento acerca do número de trabalhadores da indústria do petróleo no Brasil e a mobilidade pendular desses trabalhadores para que pudéssemos compreender a divisão territorial do trabalho do circuito.

4 Com o intuito de analisar os efeitos geoeconômicos, as hierarquias e os círculos de cooperação do circuito do petróleo, foi realizado um levantamento das empresas que prestam serviços e/ou fornecem mercadorias para a Petrobras junto ao Portal da Transparência, à Federação das Indústrias do Espírito Santo (FINDES) e nos sites das empresas. Tendo em vista que a Petrobras atua em todo território nacional, realizou-se um recorte no levantamento das empresas do círculo de cooperação do petróleo entre Rio de Janeiro e Espírito Santo. Após a identificação das empresas que formam o círculo do petróleo, foi realizada uma classificação das mesmas de acordo com a relação com as petroleiras, em especial coma Petrobras.

5 Os resultados nos revelam uma particular organização produtiva do grupo Petrobras no Brasil a partir de uma singular divisão social e territorial do trabalho que se forma no interior do circuito espacial do petróleo e de seu círculo de cooperação que implicam na produção de um espaço desigual e combinado.

\section{Os circuitos espaciais da produção e os círculos de cooperação}

6 Neste item abordaremos, num primeiro momento e brevemente, os conceitos de circuitos de produção e os círculos de cooperação e, num segundo momento, verificaremos sua funcionalidade empírica no setor petrolífero na região entre o Rio de Janeiro e o Espírito Santo.

7 Os circuitos espaciais da produção e os círculos de cooperação são conceitos da geografia e importantes ferramentas teóricas para se compreender as articulações e as implicações espaciais das atividades produtivas no contexto da globalização coordenada pelo capitalismo financeiro (MORAES, 2017).

8 De maneira geral, a noção de circuito espacial produtivo pode ser compreendida como sendo composta dos movimentos que percorrem os diferentes ciclos produtivos a partir de uma transformação primária ou inicial passando por uma gama de etapas correspondentes aos distintos processos de transformação do produto principal até chegar ao consumo final - a produção propriamente dita, a distribuição, a comercialização e o consumo (SANTOS, 1986; ARROYO,2008). Moraes (2017 p. 25) 
acrescenta que os circuitos espaciais da produção nada mais seriam do que a espacialização do encadeamento da produção-distribuição-troca-consumo. Arroyo (2008) complementa apontando que esses circuitos espaciais da produção

são formados por empresas de diversos tamanhos [que atuam em diversas escalas] voltadas para um determinado bem ou serviço, e que atingem de forma articulada diferentes frações do território. Essa articulação se expressa pelo movimento de inúmeros fluxos de produtos, ideias, ordens, informação, dinheiro, excedente. Enfim, pela circulação. Assim, cada fração do território pode ser alcançada por uma ou várias fases de um ou vários circuitos de produção, o que permite explicar sua inserção na divisão interna e internacional do trabalho (ARROYO, 2008, p. 01).

As bases do conceito de circuito espacial de produção, para a sua melhor delimitação e compreensão, enviam a uma leitura espacial do encadeamento, demonstrado por Marx, da produção-distribuição-troca-consumo que nos remete ao conceito de capital enquanto fluxo, capital que circula por e entre as diferentes fases que possibilitam, em última instância, a acumulação. Desse modo, o termo circuito contido no conceito nos remete a centralidade da circulação nesse encadeamento. Por sua vez, o termo espacial, que releva o papel ativo do espaço, nos remete a espacialidade produzida e reproduzida por essas fases. Finalmente, o termo produção nos indica que essas fases estão de certo mordo articuladas ordenadamente no interior da produção de determinados ramos ou atividades produtivas dominantes (CASTILLO e FREDERICO, 2011).

10 Vale ainda ressaltar, que os circuitos espaciais de produção e acumulação possuem a capacidade de demonstrar o uso diferenciado do espaço por parte das empresas, das instituições, dos indivíduos, bem como permite compreender a hierarquia dos lugares em diferentes escalas (SANTOS, 1986). Esses aspectos são capturados por meio de uma análise tripartite dos seguintes fenômenos: I - A configuração espacial - formas específicas de distribuição da força de trabalho, das atividades, da infraestrutura produtiva e de consumo e das condições ambientais; II - a organização espacial - a maneira como os elementos da configuração espacial se relacionam através da ação coordenada dos agentes sociais; III - fluxos de pessoas, bens, dinheiro e informação - que são responsáveis pelo fenômeno da configuração espacial, e, que, em certa medida, definem a organização social do espaço (SANTOS, 1986).

11 Em resumo, parte-se do princípio de que o circuito espacial da produção possibilita compreender como determinada atividade/produto principal (ramo, grupo ou firma) produz uma configuração e organização espacial e uma divisão social do trabalho própria que circula, movimenta e integra entre/por diferentes agentes e escalas implicando assim no processo de reprodução do capital e na conformação de um espaço geográfico desigual e combinado. Assim, como indica Santos (1986), os diferentes ramos industriais podem conformar e tipificar a relação de produção social e se poderia estudar as firmas, os setores, os ramos e suas relações sociais de produção em um conjunto dos circuitos, todos eles dariam uma configuração a um espaço dado dentro de uma região ou país, espaços subalternos, submetidos aos comandos territoriais (nacionais ou internacionais) e ao desenvolvimento desigual dos territórios industriais que se sobrepõem a outras sortes de territórios ${ }^{1}$. Estes processos somente podem ser entendidos a partir de uma perspectiva reescalonar (BRENNER, 2013 [2009]), ou seja, as formas como em escalas diversas e imbricadas se reelaboram os processos, os fluxos e os fixos das atividades econômicas sobre os territórios num movimento espaçotemporal que perpassa em sentidos diversos os lugares de inserção concreta das infraestruturas articulados aos espaços internacionais de circulação, mediados pelas 
esferas nacionais e regionais. 0 "reescalonar" é a forma concreta como se dá de forma diferencial nos lugares os processos cujos comandos se encontram em outros espaços.

Por outro lado, os círculos de cooperação podem ser compreendidos como sendo as relações estabelecidas entre os agentes e os lugares no interior de um circuito (SANTOS e SILVEIRA, 2006; MORAES, 2017). Os círculos de cooperação expressam a conexão entre as diversas etapas produtivas e os diferentes agentes que se encontram dispersos territorialmente, mas articulados pelos fluxos materiais e imateriais. Vale destacar, que no círculo de cooperação participam agentes de um circuito específico e também outros agentes, inclusive os poderes públicos e as instituições e organizações que, mesmo não atuando diretamente na atividade dominante de determinado circuito, participam ofertando serviços, equipamentos e capitais necessários ao seu desenvolvimento (CASTILLO, FREDERICO, 2011).

13 Assim, circuitos espaciais da produção e círculos de cooperação objetivam analisar os movimentos e fluxos produzidos pelos processos produtivos. 0 Primeiro tem foco sobre um determinado ramo, grupo ou firma. Já o segundo desvela a articulação entre os agentes e os lugares (SILVA, 2019). São conceitos potentes para se analisar os processos geoeconômicos no contexto de capital financeiro e de reestruturação produtiva, afinal, eles analisam de maneira conjunta as espacialidades, as escalas e os fluxos.

14 A partir dos pressupostos descritos, nas próximas partes buscaremos analisar os circuitos espaciais e os círculos de cooperação do petróleo a partir de uma análise do grupo Petrobras.

\section{O circuito espacial de produção e a divisão territorial do trabalho : o caso do grupo Petrobras}

15 De acordo com a Agência Nacional do Petróleo (ANP) a exploração e a produção de petróleo e gás no Brasil se encontram espalhada em 57 bacias sedimentares que somam uma área de $8.204 .544 \mathrm{~km}^{2}$ localizadas no continente $\left(5.414 .655 \mathrm{~km}^{2}\right)$ o no mar $\left(2.789 .889 \mathrm{~km}^{2}\right)$. Compreende-se uma bacia sedimentar como sendo uma depressão da crosta terrestre onde se acumulam rochas sedimentares que podem ser portadoras de petróleo ou gás, associados ou não (BRASIL, 1997). No que se refere à produção de petróleo, foram 944.117 milhões de barris de petróleo produzidos em 2018. 0 estado Rio de Janeiro aparece na liderança como sendo o maior produtor de petróleo (662.818 milhões de barris - 70,2\% da produção nacional) seguido pelo Espírito Santo (122.309 milhões de barris - 12,9\% da produção nacional) e São Paulo (116.464 milhões de barris$12,3 \%$ da produção nacional) (ANP, 2019). No que se refere à produção de gás o estado do Rio de Janeiro também lidera (20.197,6 milhões de $\mathrm{m}^{3}-49,4 \%$ da produção nacional) e é seguido por São Paulo (6.431,0 milhões de $\mathrm{m}^{3}-15,7 \%$ da produção nacional), Amazonas (5.216,0 milhões de $\mathrm{m}^{3}-13 \%$ da produção nacional) e Espírito Santo $(3.462,9$ milhões de $\mathrm{m}^{3}-8 \%$ da produção nacional) (ANP, 2019).

Até 1997 a Petrobras era a única companhia a explorar e produzir petróleo no Brasil, fato que mudou com a lei do petróleo (lei 9.478/97) que trouxe a abertura do circuito para novas companhias nacionais e internacionais. A participação dessas companhias, em especial as multinacionais, é significativamente crescente. Em 2011 a Petrobras havia sido responsável pela produção de $91,7 \%$ do petróleo brasileiro contra $8,22 \%$ das multinacionais e 0,08\% de outras companhias nacionais. Já em 2017, a participação da 
Petrobras caiu para $77,81 \%$ enquanto as multinacionais tiveram um aumento para 21,6\% (PETROBRAS 2012 e 2018). No gráfico 01 pode ser visualizado esse aumento da participação das multinacionais.

Gráfico 01: Produção das concessionárias que atuam na exploração de petróleo no Brasil.

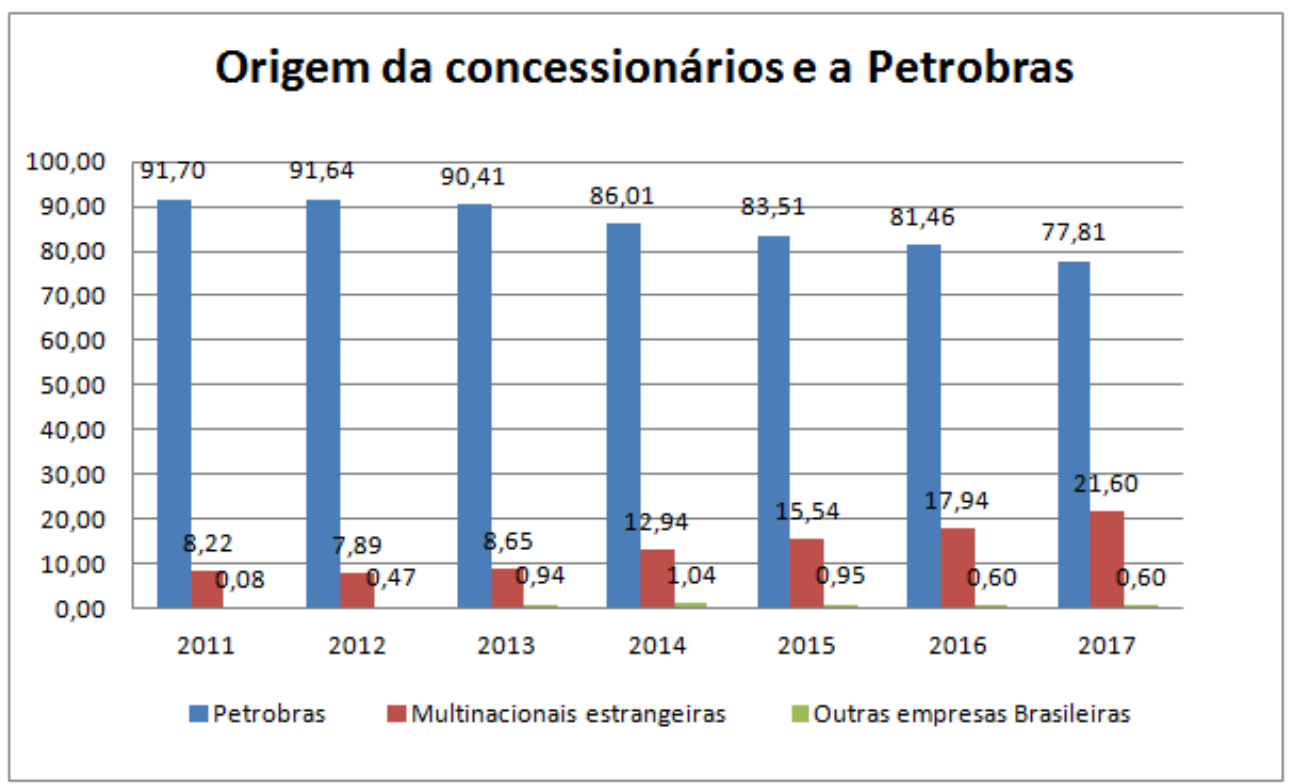

Fonte: ANP (2018)

17 A origem dessas multinacionais é diversa. Entretanto, destaca-se a participação das petroleiras norte-americanas (Chevron e Exxon dentre outras), das chinesas estatais (CNOOC e a CNODC) e das britânicas (Shell e BP) etc. No gráfico 02 pode ser visualizada a origem das petroleiras multinacionais que atuam no Brasil.

Gráfico 02: País de origem das multinacionais que atuam na exploração de petróleo no Brasil.

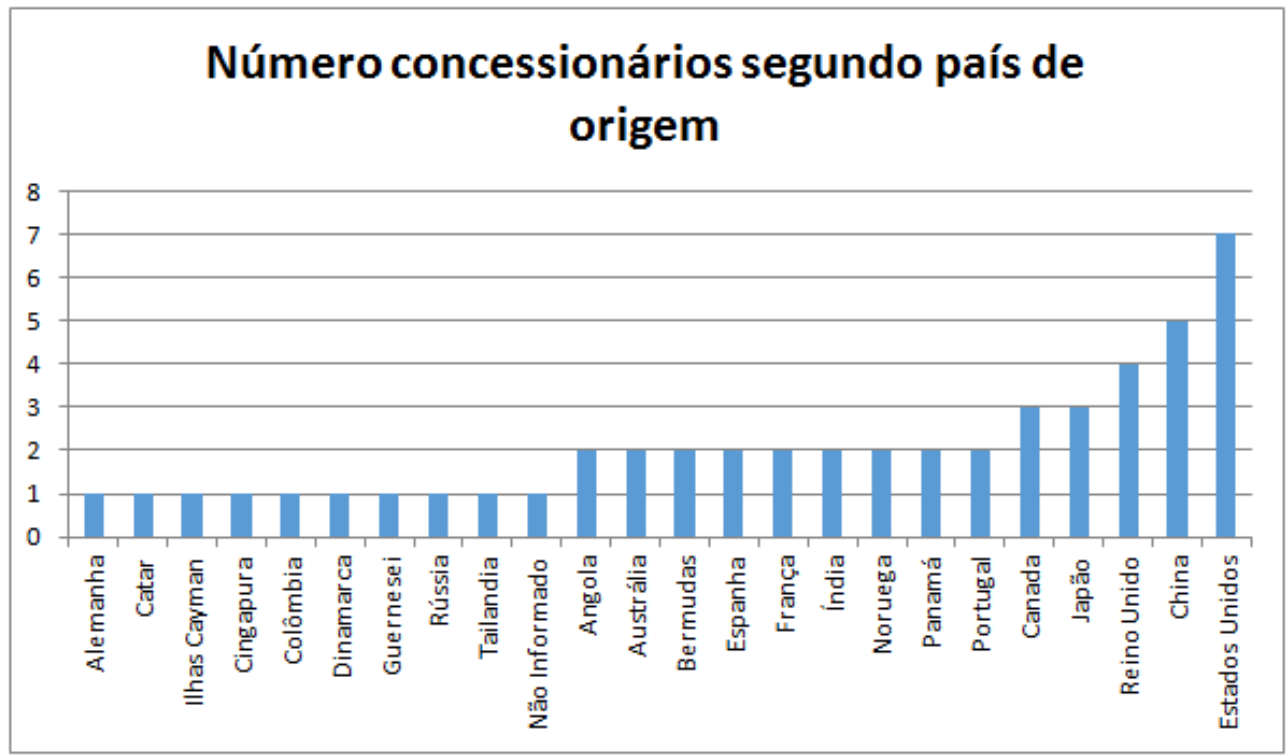

Fonte: ANP (2019) 
18 A tendência para os próximos anos é que a produção das multinacionais aumente progressivamente em função da grande quantidade de blocos exploratórios arrematados por essas companhias nas últimas rodadas de leilões da ANP e em função da privatização rampante da Petrobras onde campos e blocos estão sendo vendidos para diferentes petroleiras nacionais e multinacionais.

19 A participação do setor privado, em especial das multinacionais, também tende a ser crescente nos setores de transporte e refino de petróleo e gás uma vez que parte significativa das redes de gasodutos da Petrobras no Brasil já foi vendida e as refinarias foram colocadas à venda pela Petrobras. Malgrado a tendência de crescimento e intensificação do processo de espoliação por parte do capital internacional (ligado a petroleiras multinacionais e a fundos de investimentos) sobre a Petrobras, no contexto da atual rodada de neoliberalização ${ }^{2}$ no Brasil, a maior parte da infraestrutura ligada à produção, transporte, refino e distribuição de petróleo e gás ainda é controlada pelo grupo Petrobras. No mapa 01 pode ser observada e analisada a configuração espacial e produtiva do circuito do petróleo no Brasil.

A Petrobras controla atualmente (por enquanto) a maioria dos terminais de petróleo e gás, refinarias e estações de compressão, além disso, a companhia detém a maior parte dos dutos do país (mais de $9.000 \mathrm{~km}$ ) e das plataformas de produção de petróleo (132 plataformas de um total de 143 em operação no Brasil) (PETROBRAS e ANP, 03/2019). Entretanto, vale destacar a crescente privatização dessas infraestruturas. Como exemplo, a privatização de uma extensa malha de dutos que cortam as regiões Sudeste, Nordeste e Norte que pertencia as subsidiárias da Petrobras Nova Transportadora do Sudeste (NTS) e Transportadora Associada de Gás (TAG). A primeira teve a venda de 90\% das ações para a Nova Infraestrutura Fundo de Investimentos em Participações (FIP), gerido pela Brookfield Brasil Asset Management Investimentos Ltda., entidade afiliada ao fundo canadense Brookfield Asset Management. Na mesma data, o FIP realizou a venda de parte de suas ações na NTS para a Itaúsa - Investimentos Itaú S.A. Por sua vez, em 2019 houve a privatização da TAG que foi vendida para a francesa Engie e o fundo Caisse de Dépôt et Placement du Québec ("CDPQ") por R\$ 8,72 bilhões, foi a maior venda de ativos da Petrobras em seus 66 anos. A composição acionária atual da TAG é a seguinte: $10 \%$ da Petrobras, 58,5\% da Engie e 31,5\% do CDPQ. Evidentemente que para além da privatização, esse processo de venda de setores importantes do grupo Petrobras representa efetivamente uma perda de autonomia e uma dependência da empresa e do país em relação à circulação desta importante fonte de energia para o desenvolvimento econômico e social. 
Mapa 01: Configuração espacial e produtiva do circuito do petróleo no Brasil.

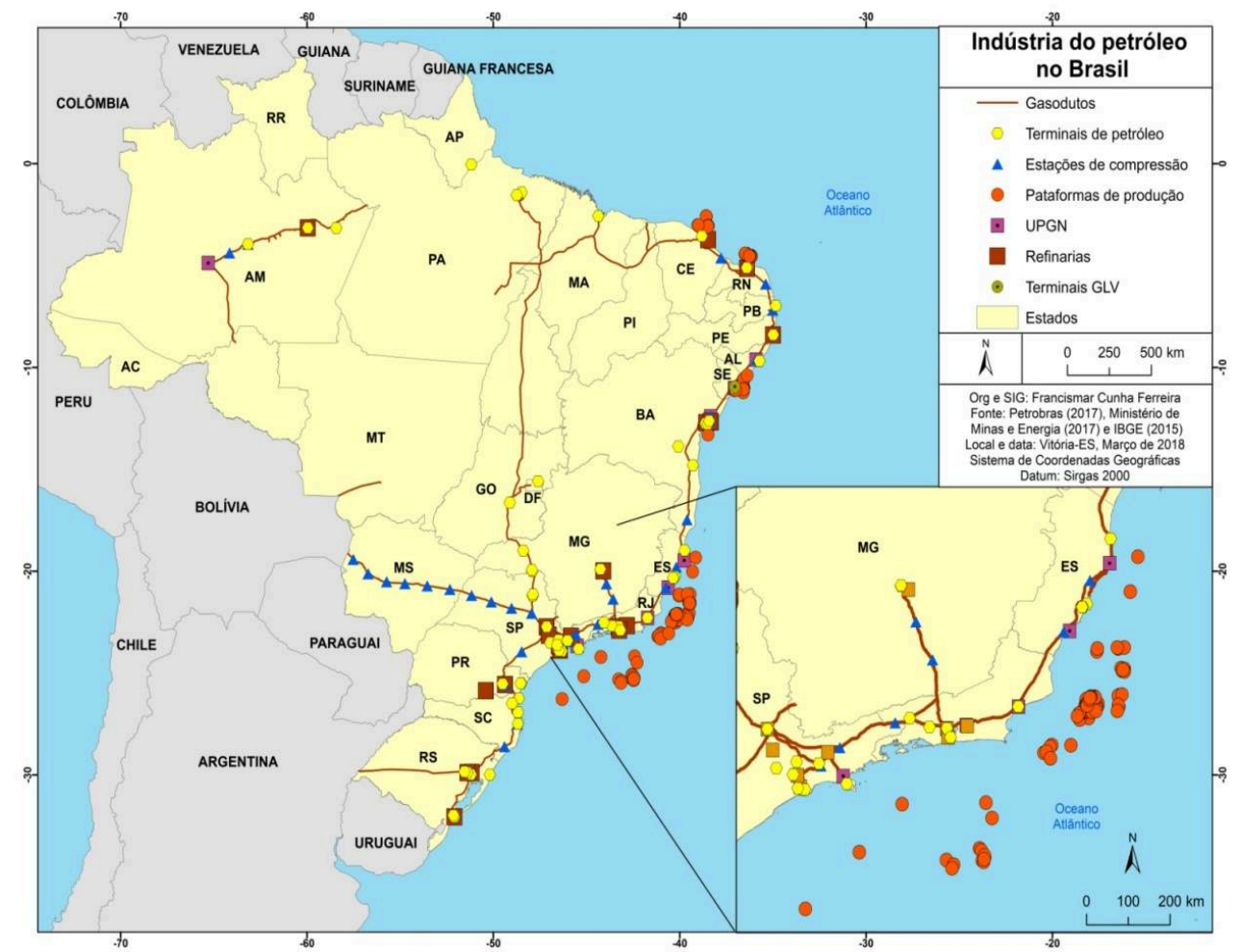

FONTE: Petrobrás (2017), Ministério de Minas e Energia (2017) e IBGE (2015). Organizado: Francismar Cunha Ferreira.

Observando o mapa 01 nota-se que as atividades da indústria petrolífera no Brasil se desenvolvem com maior intensidade na faixa litorânea do país com uma concentração, em especial no que se refere às refinarias, terminais e gasodutos, na região Centro-Sul, com destaque para região Sudeste. Por exemplo, das 15 refinarias do país, 10 se encontram na região Centro-Sul, sendo que sete ficam na região Sudeste, com destaque para São Paulo onde estão localizadas quatro delas. Além disso, três se localizam na região Nordeste e uma na região Norte. Essa concentração, em especial no estado de São Paulo, se justifica, por um lado, pela demanda histórica de petróleo e derivados pelas atividades produtivas em geral que ali são concentradas, por outro lado, pelo fato de a região Sudeste possuir as principais e maiores reservas de petróleo e gás do país.

Outro fator de destaque no mapa 01 são as plataformas de exploração de petróleo que se localizam no mar territorial do Brasil. Na presente ocasião concebemos esses empreendimentos não como uma infraestrutura como as redes de dutos e terminais, mas como uma planta industrial assim como a refinaria. Isso porque parte-se do pressuposto de que a indústria retira do meio a matéria-prima e a devolve sob uma forma transformada. As plataformas retiram o petróleo e gás do subsolo e os preparam para serem transformados. Nelas realizam-se a separação do petróleo e do gás quando os mesmos ocorrem associados, bem como a separação do gás e do petróleo da água e, finalmente, o processamento inicial do petróleo e do gás antes deles serem enviados por meio de gasodutos, oleodutos e navios petroleiros para as refinarias e plantas de tratamento de gás

Em geral as infraestruturas e as plantas industriais do circuito do petróleo apresentam particularidades quando comparadas a outros setores industriais. No que se refere a 
essas particularidades, Piquet (2007) destaca inicialmente os fatores inerentes à localização. O comportamento locacional da indústria petrolífera é determinado pela presença da fonte de matéria-prima, o petróleo e gás (ibidem, 2007). Em outros termos, enquanto os demais setores da indústria definem suas localizações a partir de um conjunto de estratégias econômicas e espaciais, no caso da indústria do petróleo, assim como de outras indústrias extrativas, a possibilidade de escolha locacional é de certa forma, inelástica em função da localização das jazidas da matéria-prima.

Esta definição da localização das atividades da indústria extrativa, especialmente do petróleo e gás, é, no entanto, relativa, pois a localização de algumas atividades da indústria do petróleo como a infraestrutura e até mesmo as plantas industriais - rede de dutos, terminais, estações de compressão, unidades de tratamento, refinarias etc. - que ultrapassam os limites do campo de produção em si são dispersas e integradas nos territórios. No capitalismo elas seguem o movimento dos "ajustes espaciais" onde tendem a estar dispostas no território com o objetivo de possibilitar a diminuição do tempo de circulação das mercadorias e de rotação e circulação do capital empregado no setor, permitindo, assim, a apropriação do mais valor e, consequentemente, a formação de excedentes (HARVEY, 2006).

Porém, as grandes infraestruturas e os grandes equipamentos, incluídos nos capitais fixos, dependem, também, das regulações dos governos, quando se promove uma "coerência estruturada" (HARVEY, 2013) por parte do Estado, este último promove uma certa estruturação em determinado espaço no processo de acumulação do capital por meio de uma regulação econômica e social, conferindo "[...] ]ao espaço coerência territorial [...] (WERNER, BRANDÃO, 2019, p.15). Há, assim, uma lógica de desenvolvimento regional que não se submete inteiramente à lógica puramente locacional e circulante do capital, o que nós poderíamos chamar de desenvolvimento territorial com intervenção estatal, por exemplo a decisão de se construir refinarias na região menos desenvolvida economicamente do país, o Nordeste, durante os governos do presidente Lula (2003-2010), obedeceram a uma lógica de expansão territorial do capital, para fornecer energia e matéria prima aos polos industriais de Suape, em Pernambuco, e a outros polos econômicos do Nordeste, mas também a uma lógica de investimento e desenvolvimento da região. Este processo manifesta, desta forma, a importância da intervenção estatal e a importância para a acumulação da regulação estatal, no entanto, esta regulação, dependendo da orientação do governo à frente do Estado, pode mais ou menos favorecer uma certa redistribuição das mais-valias e das rendas ligadas ao setor para o conjunto da sociedade e buscar um certo tipo de "desenvolvimento" territorial que não obedeça à lógica supostamente cega da acumulação, aquela que associa as práticas econômicas à pura concorrência e à competitividade entre os agentes. O Estado neste último caso, para os neoliberais, deveria exercer, de forma aparente, uma função que seria de puro enquadramento sem intervenção no jogo da "livre concorrência". Ao contrário, entretanto, a intervenção do Estado pode promover modificações na circulação do valor e da renda e na própria configuração do circuito do petróleo e no círculo de cooperação de empresas associadas, em última instância, na própria dinâmica do trabalho e da divisão territorial do trabalho: mais ou menos intensa em capital nacional e regional, mais ou menos intensiva em trabalho e em tecnologia nacional e regional. O Estado, assim, não é neutro e faz parte das relações de poderes entre classes e frações de classe. 
26 A configuração espacial e produtiva do circuito do petróleo no Brasil desenvolve uma divisão territorial do trabalho particular, mas que é estruturante do espaço e se reverbera nos capitais fixos representados pelas sondas de exploração, pelas plataformas de produção e pelas refinarias que interagem por meio das infraestruturas necessárias às conexões destes processos. Nesta unificação haverá um nivelamento para as condições gerais de reprodução do capital onde se "[...] procura garantir um espaço unificado para a circulação e para a ação do valor, em sua busca por mais valorização" (WERNER, BRANDÃO, 2019, p.12). Estes capitais fixos, em particular suas infraestruturas, poderiam ser aquilo que Werner e Brandão chamam "condição e resultado da criação de espaços unificados coercitivos e dotados de irreversibilidade" (Ibidem, p.12), mas que no nosso caso de análise podem sofrer com processos de "desinvestimentos" ou de privatização que permitiram a captação de mais-valias consideráveis pelos capitais multinacionais e uma desautonomia relativa dos espaços locais, regionais e nacionais impondo outras regras de relação socioterritoriais.

Assim, quando se trata do trabalho podemos identificar processos extremamente complexos e extremamente frágeis e reversíveis nestas condições gerais de produção associando intrinsecamente capital e trabalho, investimentos em capitais fixos e reverberações territoriais e espaciais dos circuitos espaciais do petróleo. Deste modo, de acordo com os dados do Instituto Brasileiro de Geografia e Estatística (IBGE, 2010), tinha-se no país em 2010, 164.891 trabalhadores ${ }^{3}$ ligados explicitamente à indústria do petróleo. A divisão territorial do trabalho na indústria do petróleo do Brasil pode ser visualizada no mapa 02.

Mapa 02: Divisão territorial do trabalho na indústria do petróleo no Brasil em 2010.

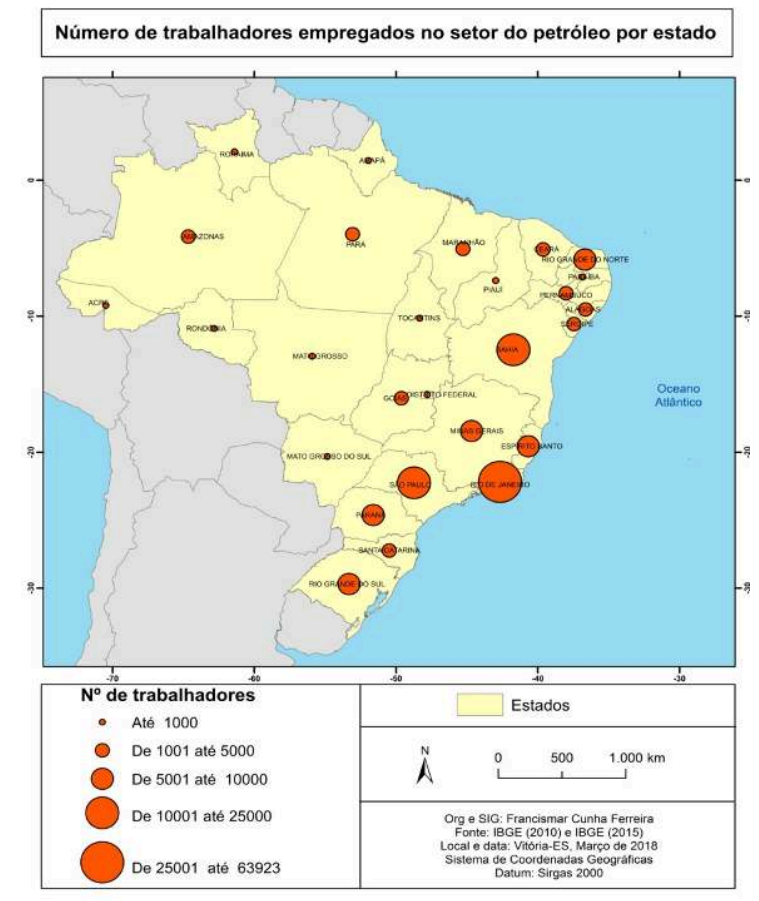

Fonte: IBGE (2010; 2015). Organizado: Franscismar Cunha Ferreira. 
Observando o mapa 02, nota-se que as regiões onde se encontra o maior número de trabalhadores são exatamente onde se tem a maior concentração de infraestruturas e unidades produtivas da indústria do petróleo. $O$ estado do Rio de Janeiro aparece com o maior número de trabalhadores, cerca de 63.923. Esse elevado número de trabalhadores se justificada devido ao fato de o estado abrigar em seu território a maior parte da produção nacional de petróleo e gás e por sediar as principais empresas petroleiras e prestadoras de serviços às indústrias do petróleo. $\mathrm{Na}$ sequência tem-se o estado da Bahia e São Paulo com respectivamente 20.265 e 19.226 trabalhadores.

Ressaltamos que os dados do IBGE (2010) consideram os trabalhadores da indústria do petróleo como um todo no Brasil. Nesse contexto, vale destacar que em 2010, somente o grupo Petrobras, conforme informações da própria empresa, possuía 80.492 trabalhadores, o que envolvia a BR distribuidora (hoje privatizada), a Transpetro e outras subsidiárias e 57.498 trabalhadores próprios da Petrobras. Além disso, a companhia contratava em 2010, 291.606 trabalhadores terceirizados. Esse número de trabalhadores somente ligados a Petrobras é bem superior aos apresentados ao IBGE (2010), pois muitos serviços terceirizados não estão classificados na CNAE como ligados ao petróleo, o que deixa os números do IBGE (2010) mais próximos de demonstrar tendências e processos do circuito do petróleo do que representar fielmente o número de trabalhadores do circuito do petróleo.

30 Mas, como já indicamos, a importância da força de trabalho vai muito além destes dados do IBGE já antigos e dos próprios dados do grupo Petrobras para a economia como um todo com seus rebatimentos espaciais e territoriais. Eduardo Costa Pinto (2019) fez um estudo sobre os impactos econômicos do investimento da indústria de petróleo na economia brasileira procurando demonstrar os efeitos da redução de investimentos e do conteúdo local no setor em termos de valor adicionado e de emprego no território brasileiro em consequência das políticas adotadas pela direção atual da Petrobras, sobretudo a partir de 2015. Ele analisou em particular a FBCF Formação Bruta de Capital Fixo - da Petrobras. A FBCF é a medida de investimento e inclui ativos fixos "tangíveis ou intangíveis" resultantes de processos de produção e utilizados repetida ou continuamente em outros processos de produção por pelo menos um ano. Estes investimentos em capitais fixos, segundo o FBPC é uma parcela do investimento que corresponde a quantidade de produtos produzidos não para serem consumidos, mas para serem utilizados no processo produtivo nos anos posteriores (COSTA PINTO, 2019, p.18, nota 16). Costa Pinto demonstrou (2019, p.18- 20) a associação direta entre os investimentos da Petrobras e a FBCF do Brasil, em particular no período que vai de 2003 até 2013 quando ocorrem os grandes investimentos na exploração e produção do petróleo do pré-sal e no processo de refino. ${ }^{4}$

31 Assim, o investimento produtivo da Petrobras tem um efeito direto sobre as atividades atinentes da construção naval e sobre trabalhadores terceirizados e diretos do setor. Segundo Costa Pinto o setor, mais a construção naval, chegaram a empregar $524 \mathrm{mil}$ trabalhadores em 2013, período do auge da atividade econômica na indústria do petróleo (dos quais 360 mil trabalhadores terceirizados da Petrobras, 86 mil do grupo Petrobras e 78 mil trabalhadores da construção naval) para em seguida com a crise econômica e política que atingiram em cheio o grupo Petrobras se passar no total para 224 mil trabalhadores em 2017: 63 mil do grupo Petrobras, 117 mil dos terceirizados do grupo Petrobras e 44 mil trabalhadores da indústria naval (se considerarmos para esta última os dados de 2016, pois não dispomos das números para 2017). Desta maneira, 
este setor, e, sobretudo a Petrobras, tem uma enorme importância tanto no emprego como sobre parcela do próprio PIB brasileiro, como demonstra Costa Pinto (2019, Idem, p.49-57), por outro lado, a queda de investimentos da Petrobras foi também acompanhada com a queda do conteúdo local no setor o que traz repercussões fenomenais para a indústria e os seus setores associados.

Isto tudo reitera o que dissemos sobre a importância da interferência do Estado numa empresa deste porte e num setor que percola suas atividades para vários outros da economia. Isto se traduz numa repercussão territorial e sobre os circuitos e os círculos de cooperação do petróleo.

Outro aspecto que chama a atenção na indústria do petróleo é exatamente a extensa e intensa mobilidade pendular do trabalho. Dos 164.891 trabalhadores do circuito do petróleo de acordo com o IBGE em 2010, 71.766 realizavam mobilidade pendular, parte interestadual (13.211 trabalhadores, $18 \%$ da força de trabalho) e a maior parte intraestadual (58.555 trabalhadores, $43,5 \%$ da força de trabalho). Destaca-se que o movimento dos trabalhadores se desenvolve na região litorânea do Brasil e os principais fluxos interestaduais têm como destino o principal centro do petróleo brasileiro, o estado do Rio de Janeiro, em cuja capital se localiza a sede da Petrobras. No mapa 03 pode ser visualizada a mobilidade pendular do trabalho na indústria do petróleo.

Mapa 03: Mobilidade pendular do trabalho na indústria do petróleo no Brasil em 2010.

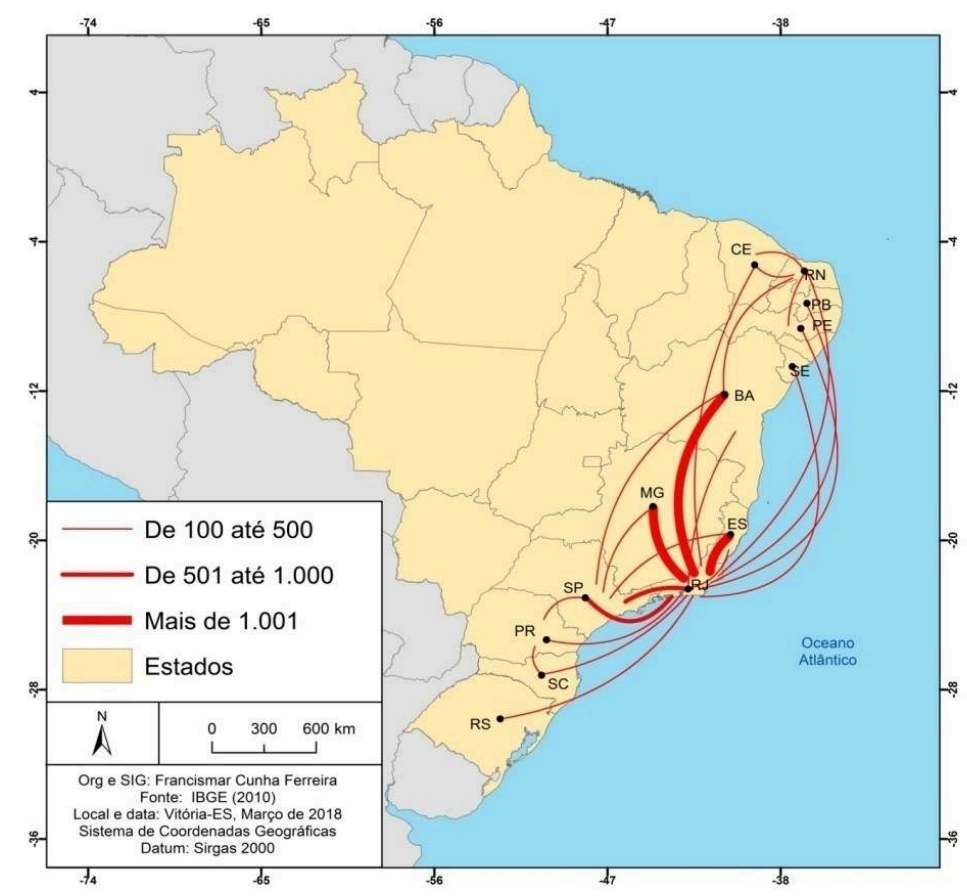

Fonte: IBGE (2010). Org: Francismar Cunha Ferreira 


\section{O círculo de cooperação do circuito do petróleo no Brasil : uma análise da região Rio de Janeiro - Espírito Santo}

Tendo analisado a organização espacial e a divisão territorial do trabalho do circuito do petróleo, em especial do grupo Petrobras, o passo seguinte consiste em analisar a relação da companhia com outros agentes, o que nos revela aspectos da divisão social do trabalho no interior do circuito. Essa articulação que se situa no âmbito dos círculos de cooperação, que podem ser compreendidos como sendo as relações estabelecidas entre os agentes e os lugares no interior de um circuito (SANTOS, SILVEIRA, 2006). Os círculos de cooperação, conforme exposto anteriormente, expressam a conexão entre as diversas etapas produtivas e os diferentes agentes que se encontram dispersos territorialmente, mas articulados pelos fluxos materiais e imateriais.

35 É importante destacar que o circuito do petróleo exige tecnologia de ponta e, nesse sentido, emergem algumas corporações que operam no setor que atuam de modo globalizado e que são especializadas em serviços e mercadorias para a indústria petrolífera. Essas empresas são denominadas de para-petroleiras, elas fornecem bens (equipamentos e materiais), tecnologia e serviços especializados para as petroleiras na exploração e produção de petróleo e gás, elas somente existem em função das petroleiras que controlam as reservas ou operam a exploração e produção e as contratam (PESSANHA, 2017).

36 Além dessas grandes empresas que atuam globalmente, existe uma série de outras empresas que atuam em escala regional ou local e que fornecem serviços e mercadorias para as indústrias petroleiras, em especial para a Petrobras, mas que também atuam fornecendo mercadorias e serviços para outros setores indústrias como siderurgia, celulose etc. Em função da diversidade de agentes, das diferentes escalas de atuação e origem do capital dos agentes que gravitam em torno da indústria do petróleo, especialmente da Petrobras, propõe-se uma tipologia dessas empresas para entender melhor suas funções e inscrições socio-territoriais em primeiro, segundo e terceiro círculos a partir do tipo de relacionamento com a indústria do petróleo. A tipologia não invalida o fato que algumas empresas possam estar presentes em mais de um círculo em função das atividades desempenhadas.

As empresas do primeiro círculo são aquelas que se organizam exclusivamente para fornecer equipamentos e máquinas - que permitem a exploração e produção do petróleo -, manutenção, transporte e serviços para as petroleiras. Predominam nesse grupo empresas multinacionais que atuam globalmente. São exemplos de empresas do primeiro círculo: SBM Offshore e Modec (multinacionais que afretam - alugam plataforma para as petroleiras), Halliburton, Baker Hughes, National Oilwell Varco, Aker Solutions, TechnipFMC, Diamond Offshore, Subsea7 e Dof Subsea (multinacionais que oferecem serviços para campos petrolíferos como engenharia, construção, perfuração e manutenção).

As empresas do segundo círculo são aquelas que fornecem mercadorias, manutenção, transporte e serviços às petroleiras e às empresas do primeiro círculo, mas que também se relacionam com outras atividades produtivas como siderurgia, mineração, celulose etc. Predominam nesse grupo empresas de engenharia, logísticas, materiais elétricos, montagem de motores etc., que são nacionais com abrangência de atuação nos 
territórios locais, regionais e nacional, bem como algumas empresas multinacionais. São exemplos destas empresas, as multinacionais Vallorec e Kaefer no setor de engenharia, as brasileiras, Falcão Bauer e BSM Engenharia com serviços de engenharia, Transuíça no setor de logística, Weg Motores com fornecimento de motores elétricos e as empresas sediadas no Espírito Santo como a Imetame ${ }^{5}$, Columbia, Cedisa e Estel do setor metalmecânica, Vix logística do setor de logística, dentre outras.

As empresas do terceiro círculo, por sua vez são aquelas que participam indiretamente do circuito do petróleo. Elas fornecem mercadorias, manutenção, transporte e serviços às indústrias do primeiro e do segundo círculo, ou seja, não se relacionam diretamente com as petroleiras. Em geral, as empresas do terceiro círculo tendem a ser empresas que atuam em escala local, geralmente estão sediadas próximas às áreas de operação e produção das empresas do primeiro e do segundo círculo e são, em geral, de pequeno porte. São exemplos dessas empresas, as indústrias, sediadas no Espírito Santo, HKM indústria e comércio, WR metal-mecânica, Casa da Solda, Geralmaq Locação de Equipamentos e Falcon Soluções Industriais, dentre outras, que fornecem serviços de locação de equipamentos e simples serviços de manutenção. Todas essas empresas citadas por último se relacionam com a Technip FMC (um multinacional que produz tubos flexíveis para as plataformas e que se localiza na região portuária da cidade de Vitória no Espírito Santo e que recentemente anunciou seu deslocamento para o Porto do Açu no Norte do Rio de Janeiro).

Em síntese, as grandes petroleiras, em particular no nosso caso a Petrobras, organizam e lideram um círculo de cooperação constituído por uma rede com empresas do primeiro, segundo e terceiro círculos. As articulações desses círculos de cooperação implicam em efeitos concretos na organização do espaço e na conformação de um desenvolvimento regional desigual e combinado em função da divisão do trabalho e da escala de atuação desses agentes. A fim de melhor compreender esse processo elencamos como exemplo a atuação deles nos territórios do Rio de Janeiro e do Espírito Santo, conforme representado no mapa 04. O mapa apresenta a densidade em $\mathrm{km}^{2} \mathrm{de}$ unidades (escritórios, fábricas, bases logísticas etc.) das empresas do primeiro e segundo círculo. Não computamos as empresas do terceiro círculo pelo fato de serem em grande número, o que inviabilizou a identificação de todas em uma escala regional como buscamos apresentar. 
Mapa 04: Primeiro e segundo círculos de "cooperação" empresariais da Petrobras e o espaço regional.

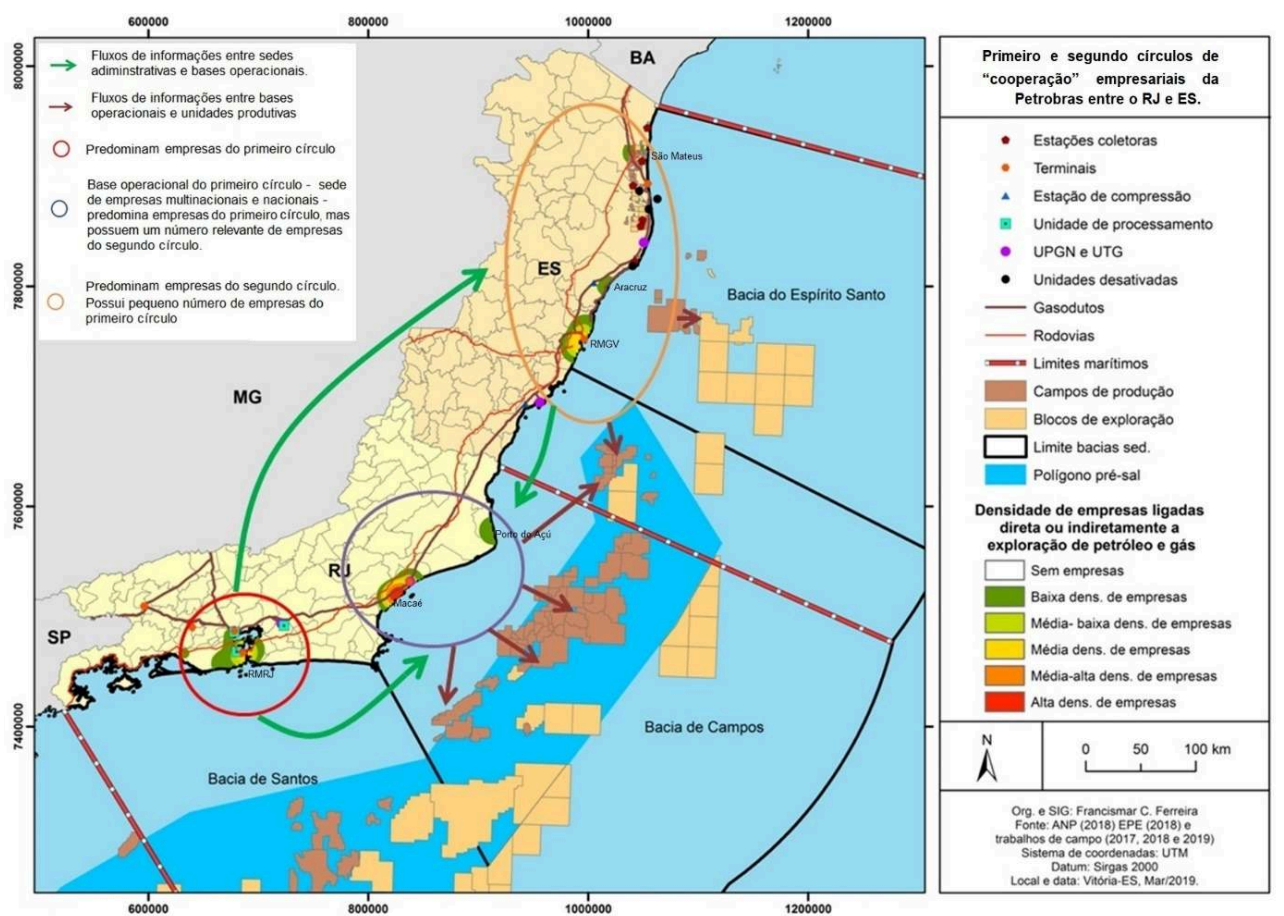

FoNTE: ANP(2018), EPE(2018) e Trabalhos de Campo realizado pelos autores nos anos de 2017,2018 e 2019. Org. Francismar C. Ferreira. distribuição espacial das empresas que prestam serviços e ou fornecem mercadorias para a Petrobras, revelando as infraestruturas ligadas ao petróleo e à Petrobras no território. Nota-se uma concentração de empresas na Região Metropolitana do Rio de Janeiro (RMRJ) e na Região Metropolitana de Vitória (RMGV), além de Macaé e o Porto do Açu no estado do Rio de Janeiro e Aracruz e São Mateus no norte do Espírito Santo.

Além da localização das empresas que se articulam com a Petrobras, se faz necessário analisar como que nessas localizações se distribui e se desenvolve a divisão social do trabalho entre as empresas do primeiro e segundo círculo e os efeitos disso na organização do espaço industrial. Sendo assim, destaca-se que na RMRJ se localizam as sedes administrativas das empresas do primeiro círculo. No Espírito Santo, têm-se poucas empresas do primeiro círculo, as que se localizam no estado são, em geral, filiais de escritórios de empresas cujas sedes no Brasil estão na RMRJ. No Espírito Santo predomina a localização de empresas do segundo círculo que ali têm suas sedes, bases produtivas e operacionais. Em Macaé e no Porto do Açu concentram-se as bases operacionais e produtivas das empresas do primeiro círculo (sediadas administrativamente na RMRJ) e do segundo círculo (sedes na RMRJ, Macaé, Espírito Santo etc.).

É importante destacar que, a Petrobras - sede no RMRJ e filial na RMGV- tem um contrato com a empresa B-Port que opera no Porto do Açu, e em função disso, todas as mercadorias que devem ser direcionadas para as plataformas são embarcadas no Porto do Açu. Nesse sentido, as empresas sediadas no Espírito Santo do segundo círculo, como Imetame, Columbia, Cedisa, Estel, por exemplo, devem enviar suas mercadorias ou instalar filiais em Macaé para ficarem próximas do Porto do Açu. 

e refere à integração entre os territórios motivada por um setor produtivo, em especial pela Petrobras por meio de sua organização espacial, e uma segunda, que nos revela um desenvolvimento desigual e combinado a partir de uma específica divisão social e territorial do trabalho onde se tem uma polarização da metrópole carioca na gestão e no comando dos processos e uma subordinação dos demais espaços, o que implica na conformação de um espaço marcado por desigualdades regionais, mas articulados por processos produtivos. Além deste aspecto se constroem estruturas industriais e infraestruturais associadas que criam marcadores territoriais fixos garantindo os fluxos dos produtos petroleiros indicando relações complexas entre o Estado, a empresa Petrobras e as empresas regionais, nacionais e multinacionais. Estas marcas do circuito espacial do petróleo engendram hierarquia das governanças, no nosso caso analisado, a bacia de atividades que atravessa e se fixa nos estados do Rio de Janeiro e Espírito Santo com uma hierarquia territorial empresarial que se sobrepõe às estruturas de governos territoriais do Estado. A problemática de uma "coerência estruturada" destas atividades demonstra a importância da regulação por parte do Estado arbitrando os interesses diversos, mas também, se a empresa Petrobras continuasse sob domínio público, o que não parece ser a estratégia apontada pelo atual governo e direção da empresa, favoreceria menos fragmentações territoriais e decisões extravertidas e de puro interesse privado e multinacional. 


\section{Considerações finais}

O circuito do petróleo no Brasil vem passando por intensas transformações na última década, em especial pelo intenso processo de privatização da Petrobras e de suas subsidiárias o que tem levado a grupos nacionais, multinacionais e fundos de investimentos a controlarem gasodutos, petroquímicas e no futuro próximo refinarias, fazendo assim com que a Petrobras deixe de ser uma indústria integrada de energia e se limitando a uma indústria de exploração de petróleo. Soma-se a isso, a crescente participação de petroleiras multinacionais na exploração e produção de petróleo. Esses processos estão implicando e implicarão em novas dinâmicas territoriais e econômicas que não foram abordados no presente trabalho, mas que merecem atenção.

A partir das análises aqui expostas sobre o circuito espacial do petróleo com foco na Petrobras foi identificada uma particular organização espacial produtiva dessa empresa, pois ela não se restringe a uma planta industrial em si, mas a um conjunto de equipamentos, de infraestruturas e plantas produtivas dispersas pelo território que se articula em escala nacional. Soma-se a isso, uma particular divisão social e territorial do trabalho que se caracteriza pela dispersão do trabalho pelo território e por uma intensa mobilidade pendular percorrendo longas distâncias.

50 Além disso, indicamos, igualmente, a produção de polarizações e hierarquias no território a partir da estruturação de círculo de cooperação do petróleo onde interagem diferentes agentes nacionais e internacionais. Esse processo foi possível de ser capturado pela categorização dos agentes em primeiro, segundo e terceiro círculos. Nesse sentido, a partir do exemplo da articulação do território dos estados do Espírito Santo e do Rio de Janeiro é possível compreender como que diferentes agentes, em diferentes escalas se articulam em torno da organização espacial produtiva e produzem uma série de fluxos materiais e imateriais que se sobrepõem às unidades territoriais políticas e que revelam a produção de um espaço desigual e combinado formado pelo circuito do petróleo.

\section{BIBLIOGRAFIA}

AGÊNCIA NACIONAL DO PETRÓLEO (ANP). Anuário estatístico brasileiro do petróleo, gás natural e biocombustíveis. Ministério de Minas e Energia. Rio de Janeiro, 2018.

AGÊNCIA NACIONAL DO PETRÓLEO (ANP). Anuário estatístico brasileiro do petróleo, gás natural e biocombustíveis. Ministério de Minas e Energia. Rio de Janeiro, 2019.

BENKO, Georges. A ciência regional. Oeiras, Portugal: Celta, 1999.

ARROYO, Mónica. A economia invisível dos pequenos. Le Monde Diplomatique Brasil, out. 2008.

BRANDÃo, Carlos. Território e desenvolvimento. As múltiplas escalas entre o local e o global. São Paulo: Editora Unicamp, 2007: 
BRENNER, N.; PECK J.; THEODORE, Após a liberalização? Revista Caderno Metropolitano, V.14, n.27, p.15-39, jan/jun 2012.

BRENNER, N. Reestruturação, reescalonamento e a questão urbana. Geousp - espaço e tempo, n. 33, PP.198-220, 2013.

CASTILHO, Ricardo; FREDERICO, Samuel. Espaço geográfico e movimento: uma reflexão sobre o conceito de circuito espacial produtivo. In: DANTAS, A.; ARROYO, M; CATAIA, M (Org.) Dos circuitos da economia urbana aos circuitos espaciais de produção: um diálogo com a teoria de Milton Santos. $1^{\circ}$. ed. Natal-RN. Sebo Vermelho, 2017.

FERREIRA, Francismar Cunha. Os arranjos espaciais produtivos: um debate inicial a partir da Petrobras. In: XVI Simpósio Nacional de Geografia Urbana (XVI SIMPURB), 2019, Vitória-ES. Anais do XVI SIMPURB, 2019.

FERREIRA, Francismar Cunha. Efeitos espaciais da indústria do petróleo no espírito santo: uma análise a partir da Petrobras. In: XIII ENANPEGE, 2019, São Paulo. Anais XIII ENANPEGE, 2019.

HARVEY, David. 0 neoliberalismo. História e implicações. São Paulo: Editora Loyola, 2011 [2005]

HERVEY, David. Os limites do capital. São Paulo: Boitempo, 2013.

HARVEY, David. A produção capitalista do espaço. 2. ed. São Paulo: Annablume, 2006.

IBGE: Censos demográficos. 2010.

IBGE, DPE-CONAC, Sistemas de Contas Nacionais 2000, nota metodológica no.19, versão 1, não datada, p. 2 disponível em:

$\mathrm{ftp}$ //ftp.ibge.gov.br/Contas_Nacionais/Sistema_de_Contas_Nacionais/Notas_Metodologicas/ 19_formacao_capital.pdf

MARX, Karl. 0 capital: crítica da economia política. Livro II. 1º. ed. São Paulo. Boitempo, 2014.

MORAES, Antonio Carlos Robert. Os circuitos espaciais da produção e os círculos de cooperação no espaço. In: DANTAS, A.; ARROYO, M; CATAIA, M (Org.) Dos circuitos da economia urbana aos circuitos espaciais de produção: um diálogo com a teoria de Milton Santos. $1^{\circ}$. ed. Natal-RN. Sebo Vermelho, 2017.

PECK, J. Geography and Public Police: Constructions of Neoliberalism. Progress in Human Geography, 28/03, 2004, p.392-405. Doi: 10.1191/0309132504ph492pr

PECK, J; TICKEL, A. Neoliberalizing Space. Antipode, 34/3, 2002, p.380-404. Doi: 10.1111/1467-8330.00247

PESSANHA, Roberto Moraes. A relação transescalar e multidimensional "Petróleo-Porto" como produtora de novas territorialidades. Tese de doutorado. Programa de Pós-Graduação em Políticas e Formação Humana (PPFH). Universidade Estadual do Rio de Janeiro. Rio de Janeiro, 2017.

PESSANHA, R.M. e OLIVEIRA, F. Os circuitos espaciais de produção do petróleo no Rio de Janeiro e em São Paulo: formação e integração da megarregião Rio - SP. Espaço e Economia. Revista brasileira de Geografia Econômica, n.15, 2019, p.1-5. Doi: 10.4000/espacoeconomia.6442

PINTO, E.C.; DWECK, E. Impactos econômicos do investimento da indústria de petróleo: desinvestimento da Petrobras, Conteúdo Local e Matriz de Absorção de Investimento (MAI), 2019, texto inédito.

PIQUET, R. Indústria do petróleo e dinâmica regional: reflexões teórico-metodológicas. in: PIQUET, R.; SERRA, R. (Orgs). Petróleo e região no Brasil, o desafio da abundância. Rio de Janeiro: Garamond, 2007. 
SIMON, Mohun. Divisão social do trabalho. In BOTTOMORE, Tom. Dicionário do pensamento marxista. Rio de Janeiro: J. Zahar, 2001.

SANTOS, M. Circuitos espaciais da produção: um comentário. In: SOUZA, Maria Adélia de; SANTOS, Milton (Org.). A construção do espaço. São Paulo: Nobel, 1986. p. 121-134.

SANTOS, Milton; SILVEIRA, María Laura. o Brasil. Território e Sociedade no início do o século XXI. 9º ed. Rio de Janeiro, Record, 2006.

WERNER, D. E BRANDÃO, C. Infraestruturas e produção social do espaço: anotações sobre suas principais mediações teóricas. Revista Brasileira de Gestão e Desenvolvimento Regional G\&DR. V. 15, N. 5, P. 287-301, set-dez/2019. Disponível em < https://www.rbgdr.net/revista/index.php/rbgdr/ article/view/5045/833>. Acesso em 15/10/2020.

ZANOTELLI, C. L., DOTA, E. M. e FERREIRA, F. C. A bacia urbano-regional do petróleo da zona costeira do Espírito Santo e do Rio de Janeiro. In: Anais do XV Simpósio de Geografia Urbana (XV Simpurb), Salvador 2017.

ZANOTELLI, C. L. Elementos preliminares sobre a "desindustrialização", a financeirização e a geografia política da crise no Brasil In OLIVEIRA, F., et al. Espaço e economia. Geografia econômica e a economia política. Rio de Janeiro: Consequência, 2019.

ZANOTELLI, C.L; DOTA, M.D. FERREIRA, F.C; RODRIGUES, R.N. Bacia urbano-regional do petróleo: a zona costeira do Espírito Santo associada ao estado do Rio de Janeiro. Confins [Online], 41 | 2019, URL: http://journals.openedition.org/confins/21754. Acessado em : 21/09/2020

ZANOTELLI, C. L; MEDINA, J; FERREIRA, F. C; ADÃO, M, O, F. A notícia como máquina de guerra: Análise sobre a Petrobras e as referências à produção de Petróleo e Gás nos Meios de Comunicação de Massa. EDUFES, Vitória, 2019.

\section{NOTAS}

1. Ver sobre uma leitura destas relações de circuitos em Milton Santos e Marx, Zanotelli (2019). 2. Sobre a importância e complexidade das diferentes rodadas de neoliberalização em função dos territórios onde elas ocorrem, pode-se consultar o já clássico trabalho de Harvey, 0 neoliberalismo. História e implicações, 2011 [2005 e 2008] que diferencia o neoliberalismo como teoria e suas aplicações concretas, o neoliberalismo "real". Aspectos que já haviam sido acentuados por PECK (2004) e PECK e TICKELL (2002). Esta definição da "neoliberalização" foi explicitada da seguinte maneira em artigo de 2012 publicado no Brasil [2010 para o original] por Brenner, Peck e Theodore como sendo "[...] uma tendência histórica específica, desenvolvida de maneira desigual híbrida e padronizada de reestruturação regulatória disciplinada pelo mercado" (2012, p.18).

3. Para a identificação do número de trabalhadores da indústria do petróleo considerou-se no censo de 2010 a CNAE domiciliar 2.0 e as seguintes variáveis: 06000 - Extração de petróleo e gás natural, 19020 - Fabricação de produtos derivados do petróleo e 35021 - Produção e distribuição de combustíveis gasosos por redes urbanas. Sabe-se que o número de trabalhadores, pode ser, e é bem maior, pois não se contabiliza no presente cálculo alguns segmentos que se articulam indiretamente com a indústria do petróleo. Utilizaremos estes dados defasados de 2010 porque eles nos permitem localizar por estado os efetivos de trabalhadores e nos dar uma ideia do espraimento e da circulação desta força de trabalho, mas outros estudos mais regionalizados a partir da RAIS (Ministério do Trabalho) até 2018 permitem de se ter uma estimativa do conjunto dos trabalhadores do setor mais recente e de seu declínio em muitos estados e regiões. (ZANOTELLI, et. al., 2019). 
4. Segundo nota metodológica do o IBGE "A formação bruta de capital fixo (FBCF) é a operação do Sistema de Contas Nacionais ( $\mathrm{SCN}$ ) que registra a ampliação da capacidade produtiva futura de uma economia por meio de investimentos correntes em ativos fixos, ou seja, bens produzidos factíveis de utilização repetida e contínua em outros processos produtivos por tempo superior a um ano sem, no entanto, serem efetivamente consumidos pelos mesmos." (IBGE, Sistema de Contas Nacionais 2000, S/D).

5. A Empresa capixaba Imetame é um agente muito peculiar no circuito e no circulo de cooperação do petróleo. Ela se constituiu inicialmente como uma indústria do segmento de metalmecânica fornecendo serviços para as indústrias de celulose e siderúrgicas no Espírito Santo. Entretanto, posteriormente a indústria passou também a fornecer serviços ligados a manutenção de plataformas diretamente para a Petrobras, fazendo assim com que ela se apresentasse como uma empresa do segundo círculo. Ao mesmo tempo, a Imetame também passou a fornecer serviços para outras empresas multinacionais do segundo circulo como a norueguesa Aker Solutions, a francesa Technip, a japonesa Modec, etc. Essas relações com as empresas do segundo círculo fazem com que a Imetame também seja uma empresa que compõe o terceiro circulo. Entretanto, a Imetame passou a adquirir concessão de blocos e campos de exploração e produtos de petróleo e gás no Espírito Santo, no Rio Grande do Norte, na Bahia e em Minas Gerais e passou, assim, a ser uma petroleira.

6. Mais informações sobre a integração entre ES e RJ (bacia urbano regional) promovido pela atividade petrolífera pode ser visto em Zanotelli et. al. 2019.

\section{RESUMOS}

O trabalho realiza uma análise sobre o circuito espacial produtivo da indústria petrolífera no Brasil com um enfoque na Petrobras e em particular na região entre o Espírito Santo e o Rio de Janeiro. Nota-se que o circuito do petróleo apresenta uma singular organização espacial e produtiva industrial que, na busca por valorização de capital, desenvolve uma divisão social do trabalho e uma organização espacial específica bem como produz e sobredetermina uma série de fluxos materiais e imateriais no espaço geográfico e implica em diversos efeitos territoriais, sociais, econômicos, ambientais, que em última instância contribuem para a produção e conformação de um espaço desigual e combinado.

This paper analyzes the spatial circuit of production in the oil industry in Brazil, focusing on Petrobras and in particular in the region between Espírito Santo and Rio de Janeiro. The oil circuit production has a unique spatial and productive organization that, due to processes of capital appreciation, creates a social division of labor and a specific spatial organization. At the same time produces the conditions in a series of material and immaterial flows in the geographical space that implies many social, economic and environmental effects that ultimately contribute to the production and the shaping of an uneven and combined space.

L'article analyse le circuit spatial productif de l'industrie pétrolière au Brésil a partir de l'étude de cas de l'inscription territoriale de l'entreprise brésilienne Petrobras dans la région située entre les états de Rio de Janeiro et de l'Espírito Santo. Le circuit pétrolier a un aménagement industriel et spatial uniques, dans la recherche de la valorisation du capital s'adopte une division sociale du travail et un aménagement de l'espace particuliers. Il engendre et surdétermine, ainsi, 
une série des flux matériels et immatériels qui provoquent des effets sociaux, économiques et environnementaux et, ainsi, renforcent les inégalités territoriales dans un pays déjà soumis à de fortes tensions socio-territoriales.

El trabajo analiza el circuito productivo espacial de la industria petrolera en Brasil con un enfoque en Petrobras, entrado en la región de Espírito Santo y Río de Janeiro. Cabe señalar que el circuito petrolero tiene una organización espacial particular, de su producción y de su industria asociada. Ella busca una revalorización del capital, desarrolla una división social del trabajo y una organización específica, que se manifiesta en una serie de flujos materiales e inmateriales en el espacio geográfico e implica varios efectos territoriales, sociales, económicos y ambientales, los que en última instancia contribuyen a la producción y conformación de un espacio desigual y combinado.

\section{ÍNDICE}

Mots-clés: circuit spatial de production, industrie, pétrole, Petrobras, Brésil.

Palabras claves: Circuito de producción espacial, industria, petróleo, Petrobras, Brasil.

Palavras-chave: circuito espacial da produção, indústria, petróleo, Petrobras, Brasil.

Keywords: spatial circuit of production, industry, oil, Petrobras, Brazil

\section{AUTORES}

\section{FRANCISMAR CUNHA FERREIRA}

Doutorando em Geografia pelo Programa de Pós-Graduação em Geografia da UFES. francismar.cunha@gmail.com

\section{CLÁUDIO LUIZ ZANOTELLI}

Professor do Departamento de Geografia do Programa de Pós-Graduação em Geografia da UFES.

clzanotelli@ahoo.com.br 